\title{
Immune Checkpoint Inhibitor-Associated Scleroderma-Like Syndrome: A Report of a Pembrolizumab-Induced "Eosinophilic Fasciitis- Like" Case and a Review of the Literature
}

\author{
Christina Salamaliki · Elena E. Solomou $\cdot$ Stamatis-Nick C. Liossis (D)
}

Received: September 14, 2020 / Accepted: October 8, 2020 / Published online: October 16, 2020

(c) The Author(s) 2020

\begin{abstract}
Immune checkpoint inhibitors are a promising new therapeutic strategy in oncology that aims to eliminate cancer cells by enhancing patients' immune response against tumor antigens. Despite their beneficial effects, immune checkpoint inhibitors are also responsible for a plethora of autoimmune manifestations, known as immune-related adverse events. We present a case of eosinophilic fasciitis-like disorder in an 81-year-old patient treated with the programmed death cell protein 1 inhibitor pembrolizumab for non-small-cell lung cancer. The patient developed characteristic indurated skin lesions in his limbs after $1 \frac{1}{2}$ years of treatment with pembrolizumab and a typical "groove sign." Raynaud's syndrome was absent. A fullthickness biopsy confirmed the clinical diagnosis of an "EF-like" condition. Neither peripheral eosinophilia nor eosinophilic infiltrates in the skin biopsy were found. His symptoms improved after a 2.5-month CPI discontinuation and treatment with $16 \mathrm{mg}$ of
\end{abstract}

C. Salamaliki · S.-N. C. Liossis $(\bowtie)$

Division of Rheumatology, Department of Internal

Medicine, University of Patras Medical School,

Patras, Greece

e-mail: snliossis@med.upatras.gr

E. E. Solomou

Department of Internal Medicine, University of

Patras Medical School, Patras, Greece methylprednisolone slowly tapered to a dose of $4 \mathrm{mg}$. Eosinophilic fasciitis is a rare immunerelated adverse event of CPI treatment; our literature search identified only 12 cases that fulfill the criteria of EF in patients receiving CPIs.

Keywords: Checkpoint inhibitors; Eosinophilic fasciitis; Immune-related adverse event; PD-1 inhibitor; Pembrolizumab

\section{Key Summary Points}

Eosinophilic fasciitis (EF) has rarely been reported to be induced by checkpoint inhibitors.

The absence of Raynaud's phenomenon along with a positive "groove sign" is essential for clinical diagnosis of EF.

Early diagnosis is straightforward, and prompt management is necessary.

Only 13 cases of checkpoint inhibitorassociated EF, including our report, have been published so far. 


\section{DIGITAL FEATURES}

This article is published with digital features, including a summary slide, to facilitate understanding of the article. To view digital features for this article go to https://doi.org/10.6084/ m9.figshare.13066730.

\section{CASE PRESENTATION}

An 81-year-old Caucasian man presented to the Rheumatology Outpatient Clinic complaining about painful and indurated skin lesions in the upper and lower extremities during the last 3 months, initially affecting his thighs bilaterally. He had been diagnosed with non-small-cell lung cancer (NSCLC) 1 1/2 years ago and since then had been treated with the programmed death cell protein 1 (PD-1) inhibitor pembrolizumab. He had already undergone a fullthickness skin biopsy of the lesion on his right leg revealing scleroderma-like features: thickening and hyalinization of the connective tissue of the deep dermis, subcutaneous fat and muscular fascia, perivascular and focal interstitial lymphocytic and plasma cell infiltrates in the subcutaneous fat and localized atrophy of the adnexal structures. No eosinophilic infiltrates were found. He had been receiving $16 \mathrm{mg}$ of methylprednisolone and $2 \mathrm{~g}$ of mycophenolate mofetil daily for the last 10 days since he had been initially diagnosed with scleroderma.

On his first visit, the patient denied Raynaud's syndrome, dyspnea, gastroesophageal reflux, joint pain, diarrhea or other clinical manifestations compatible with systemic scleroderma or other connective tissue disorders.

His clinical examination revealed sclerotic skin lesions on his legs and forearms, sparing the fingers, trunk and face, and a linear depression of the skin along the course of the veins especially on the forearms, a positive "groove sign" (Fig. 1). Ulcers, telangiectasia, joint sensitivity and inflammation were not present according to the thorough clinical examination.

The patient had a positive anti-nuclear antibody (ANA) test with a titer of $1 / 160$, normal eosinophil counts (while receiving

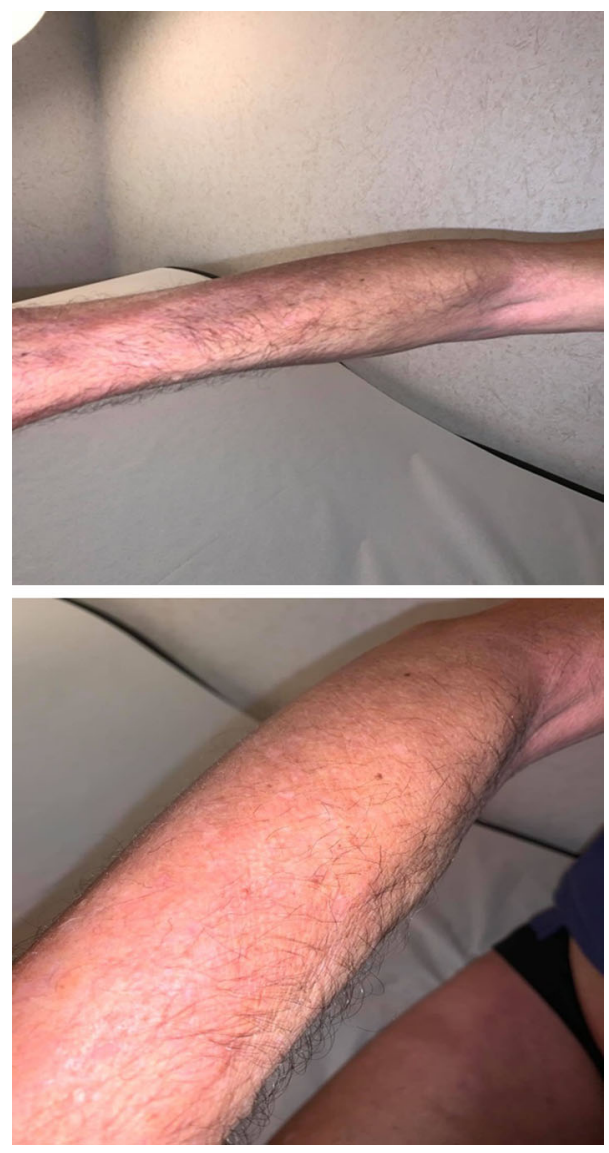

Fig. 1 Eosinophilic fasciitis of the forearm with a positive groove sign

corticosteroids) and no other remarkable laboratory findings. Erythrocyte sedimentation rate (ESR) and C-reactive protein levels were not available on his first visit.

Due to the lack of systemic manifestations, the diagnosis of systemic sclerosis was not substantiated. However, based on the localized cutaneous induration, positive groove sign and absence of Raynaud's syndrome, the diagnosis of eosinophilic fasciitis (EF) was made. The histopathologic findings confirmed the diagnosis of a scleroderma-like disorder affecting the fascia.

The high incidence of immune-related adverse events (irAEs) due to the treatment with checkpoint inhibitors (CPIs) and the correlation of the onset of patient's symptoms to the initiation of pembrolizumab made the latter a potential cause of these EF-like manifestations. 
Therefore, pembrolizumab was temporarily discontinued. The patient remained on $16 \mathrm{mg}$ methylprednisolone per day for the next 3 weeks, and the mycophenolate mofetil was withdrawn.

During follow-up, skin sclerosis was improved but not eliminated, and eosinophil counts remained within the normal range. The corticosteroids were slowly tapered to a dose of $4 \mathrm{mg}$ daily, and pembrolizumab was re-administered after having been withheld for 2.5 months. Until his last evaluation, he had shown a complete response to pembrolizumab.

Written informed consent was obtained from the patient for publication of this case report and accompanying images.

\section{DISCUSSION}

Immune checkpoints are inhibitory pathways of the immune system responsible for maintaining self-tolerance by regulating the duration and amplitude of immune responses in peripheral tissues [1]. Among immune checkpoints, the role of PD-1 and its ligand PDL- 1 and cytotoxic T-lymphocyte-associated protein 4 (CTLA4) in immune regulation is well established. CPIs are antibodies targeting the inhibitory molecules PD-1, PDL- 1 and CTLA- 4 on the surface of $T$ cells, antigen-presenting cells and cancer cells, thus enhancing $\mathrm{T}$ cell activation and the host's antitumor immunity. The introduction of CPIs has revolutionized the therapeutic approach in oncology as far as many types of cancer are concerned, such as melanoma and NSCLC. Among the most used CPIs are the PD-1 inhibitors nivolumab and pembrolizumab and the CTLA-4 inhibitor ipilimumab.

The potential of CPIs to favor the T effector responses versus the regulatory ones is thought to be responsible for irAEs affecting almost every organ. Rheumatologic irAEs are common and well described in the current literature. While arthralgia, myalgia, arthritis and myositis are some of the most common musculoskeletal rheumatic manifestations, scleroderma and scleroderma-like cases related to CPIs are only rarely described among the non-musculoskeletal rheumatic irAEs [2-8].

Herein, we present an "EF-like" case in a patient treated with pembrolizumab for NSCLC. $\mathrm{EF}$ is a rare condition in the spectrum of scleroderma-like disorders. Its clinical manifestations include an early inflammatory phase, characterized by symmetric localized swelling of the soft tissues, with a "peau d'orange" appearance, followed by induration and thickening. The thickened dermis of the affected areas attaches on the underlying muscular fascia, and a groove sign usually appears along the course of the veins. The face and hands are generally spared $[9,10]$.

Peripheral blood eosinophilia, hypergammaglobulinemia and elevated ESR and serum aldolase levels are the main laboratory findings $[9,11]$. Marked eosinophilia may be an early but temporary finding in the course of the disease [12]. In one series, peripheral blood eosinophilia was seen in 33 of 52 patients, hypergammaglobulinemia in 17 of 49 and elevated ESR in 15 of 52 [13]. Full-thickness biopsies from the affected areas show fibrosis of the subcutaneous connective tissue, cellular infiltration by eosinophills and monocytes and thickening of the fascia. However, histopathologic infiltration of eosinophils is not mandatory to establish the diagnosis [11]. Thus, EF must be differentiated from progressive systemic sclerosis (PSS) and morphea based on its clinical rather than pathologic features.

Jinnin et al. have recently proposed diagnostic criteria for EF [11]. We found 12 published cases that fulfill the criteria of EF in patients receiving CPIs (Table 1) [14-23].

Eight patients were treated for melanoma, one for bladder cancer, one for triple-negative breast cancer and three for NCSLC (including current case). Six patients were receiving nivolumab (one of whom had initially received combination therapy with ipilimumab plus nivolumab), 5 out of 13 pembrolizumab and 2 atezolizumab. Average time before the onset of symptoms was 12.8 for nivolumab (including the case with ipilimumab combination), whereas for pembrolizumab the mean time was 14.8 months. Moreover, in two of the cases, EF was combined with major non-rheumatic irAEs 


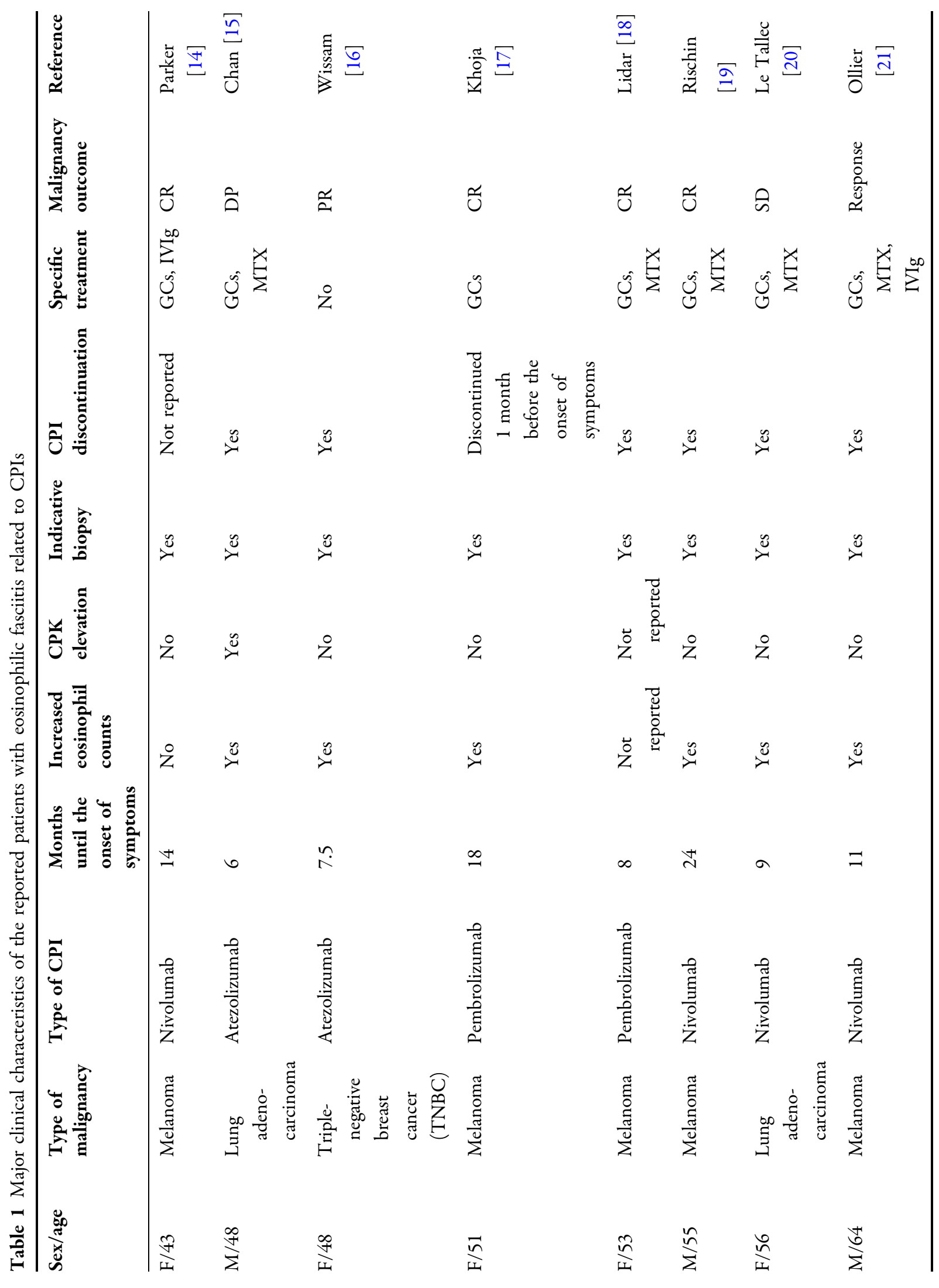




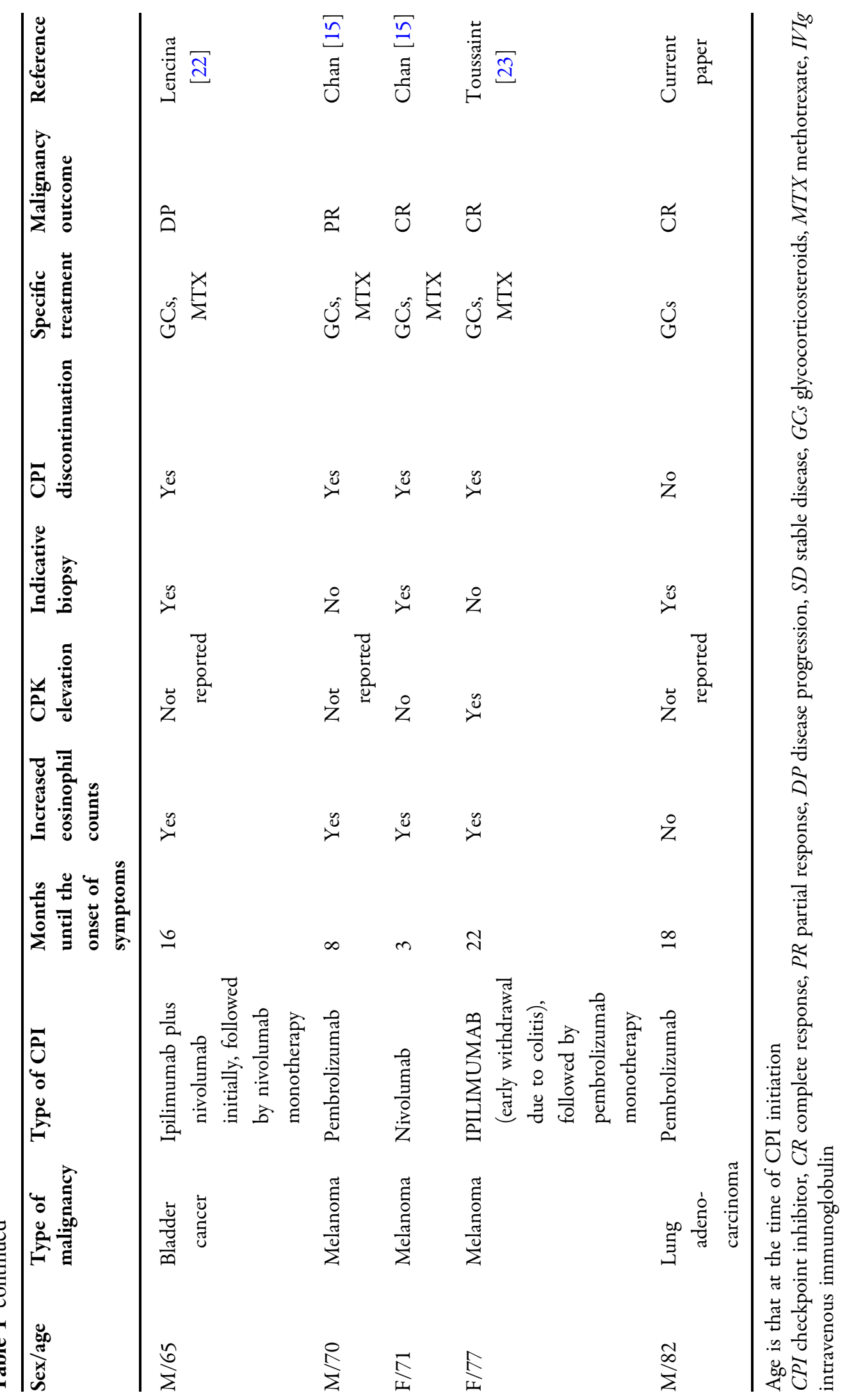


(autoimmune cholangitis [20], autoimmune encephalopathy [17]). Interestingly, most of the patients (10 out of 13) had either a complete or a partial response of the underlying malignancy, one had stable disease, and only two patients had disease progression. All patients received corticosteroids except for one case in which CPI discontinuation proved beneficial with no further treatment. In most patients MTX had to be co-administered.

Fasciitis with concomitant myositis, but without the clinical manifestations of $\mathrm{EF}$, because of checkpoint inhibitor therapy, has been also described. These patients did not have peau d'orange or groove signs. Our department has described a case of a 64-year-old man treated with nivolumab who experienced diffuse pain and swelling of the hands, knees and feet and tenton crepitus in whom myofasciitis and tenosynovitis were shown in MRI images [24]. Similar cases of myofasciitis have been described by Kobak [25] (1 case), Narváez et al. [26] (2 cases) and Chan et al. [15] (1 case). According to a recent study, imaging evidence of myofasciitis is a prominent finding among patients with CPI-induced musculosceletal manifestations [27].

In conclusion, EF may be a rare but easy-todiagnose irAE that, although non-lethal, affects patients' quality of life and treatment compliance and requires high clinical suspicion and proper management. Correlation of irAEs to a favorable antitumor outcome has been claimed; however, this has yet to be established.

\section{ACKNOWLEDGEMENTS}

Funding. No funding or sponsorship was received for this study or publication of this article. The Rapid Service Fee was funded by the authors.

Authorship. All named authors meet the International Committee of Medical Journal Editors (ICMJE) criteria for authorship for this manuscript, take responsibility for the integrity of the work as a whole, and have given final approval for the version to be published.
Disclosures. Christina Salamaliki, Elena E. Solomou and Stamatis-Nick C. Liossis have nothing to disclose.

Compliance with Ethics Guidelines. Written informed consent was obtained from the patient for publication of this case report and accompanying images.

Open Access. This article is licensed under a Creative Commons Attribution-NonCommercial 4.0 International License, which permits any non-commercial use, sharing, adaptation, distribution and reproduction in any medium or format, as long as you give appropriate credit to the original author(s) and the source, provide a link to the Creative Commons licence, and indicate if changes were made. The images or other third party material in this article are included in the article's Creative Commons licence, unless indicated otherwise in a credit line to the material. If material is not included in the article's Creative Commons licence and your intended use is not permitted by statutory regulation or exceeds the permitted use, you will need to obtain permission directly from the copyright holder. To view a copy of this licence, visit http://creativecommons.org/licenses/bync/4.0/.

\section{REFERENCES}

1. Pardoll DM. The blockade of immune checkpoints in cancer immunotherapy. Nat Rev Cancer. 2012;12(4):252-64. https://doi.org/10.1038/ nrc3239.

2. Cappelli LC, Gutierrez AK, Bingham CO, Shah AA. Rheumatic and musculoskeletal immune-related adverse events due to immune checkpoint inhibitors: a systematic review of the literature. Arthritis Care Res. 2017;69(11):1751-63. https://doi.org/10. 1002/acr.23177.

3. Abdel-Wahab N, Suarez-Almazor ME. Frequency and distribution of various rheumatic disorders associated with checkpoint inhibitor therapy. Rheumatol (United Kingdom). 2019;58:vii40-8. https://doi.org/10.1093/rheumatology/kez297.

4. Melissaropoulos K, Klavdianou K, Filippopoulou A, Kalofonou F, Kalofonos H, Daoussis D. Rheumatic 
manifestations in patients treated with immune checkpoint inhibitors. Int J Mol Sci. 2020;21(9): 1-18. https://doi.org/10.3390/ijms21093389.

5. Roberts J, Ennis D, Hudson M, et al. Rheumatic immune-related adverse events associated with cancer immunotherapy: a nationwide multi-center cohort. Autoimmun Rev. 2020;19:102595. https:// doi.org/10.1016/j.autrev.2020.102595.

6. Cappelli LC, Shah AA, Iii COB. Immune-related adverse effects of cancer immunotherapy-implications for rheumatology. Rheumatic Disease Clin N Am. 2017;43:21224.

7. Mitchell EL, Lau PKH, Khoo C, et al. Rheumatic immune-related adverse events secondary to antiprogrammed death- 1 antibodies and preliminary analysis on the impact of corticosteroids on antitumour response: a case series. Eur J Cancer. 2018;105:88-102. https://doi.org/10.1016/j.ejca. 2018.09.027.

8. Kostine M, Truchetet ME, Schaeverbeke T. Clinical characteristics of rheumatic syndromes associated with checkpoint inhibitors therapy. Rheumatol (United Kingdom). 2019;58:vii 68-vii 74. https:// doi.org/10.1093/rheumatology/kez295.

9. Pinal-Fernandez I, Selva-O'Callaghan A, Grau JM. Diagnosis and classification of eosinophilic fasciitis. Autoimmun Rev. 2014;13(4-5):379-82. https://doi. org/10.1016/j.autrev.2014.01.019.

10. Boin F, Hummers LK. Scleroderma-like fibrosing disorders. Rheum Clin Disord. 2009;34(1):199-220. https://doi.org/10.1016/j.rdc.2007.11.001.

11. Jinnin M, Yamamoto T, Asano Y, et al. Diagnostic criteria, severity classification and guidelines of eosinophilic fasciitis. J Dermatol. 2018;45(8): 881-90. https://doi.org/10.1111/1346-8138.14160.

12. Islam MN, Islam MA, Abdal SJ, Azad MAK, Ahmedullah AK, Haq SA. Eosinophilic fasciitis: What matters in management in a developing country-a case report with two and a half-year follow-up. J Heal Popul Nutr. 2012;30(1):117-20. https://doi.org/10.3329/jhpn.v30i1.11292.

13. Lakhanpal S, Ginsburg WW, Michet CJ, Doyle JA, Moore SB. Eosinophilic fasciitis: clinical spectrum and therapeutic response in 52 cases. Semin Arthritis Rheum. 1988;17(4):221-31. https://doi. org/10.1016/0049-0172(88)90008-X.

14. Parker MJS, Roberts ME, Lorigan PC, Du Plessis DG, Chinoy H. Autoimmune fasciitis triggered by the anti-programmed cell death-1 monoclonal antibody nivolumab. BMJ Case Rep. 2018;2018:3-6. https://doi.org/10.1136/bcr-2017-223249.
15. Chan KK, Magro C, Shoushtari A, et al. Eosinophilic fasciitis following checkpoint inhibitor therapy: four cases and a review of literature. Oncologist. 2020;25(2):140-9. https://doi.org/10.1634/ theoncologist.2019-0508.

16. Wissam Y, Belcaid L, Wittoek R, et al. Eosinophilic fasciitis in a patient treated by atezolizumab for metastatic triple-negative breast cancer. J Immunother Precis Oncol. 2019;2(3):101. https://doi. org/10.4103/jipo.jipo_8_19.

17. Khoja L, Maurice C, Chappell M, et al. Eosinophilic fasciitis and acute encephalopathy toxicity from pembrolizumab treatment of a patient with metastatic melanoma. Cancer Immunol Res. 2016;4(3): 175-8. https://doi.org/10.1158/2326-6066.CIR-150186.

18. Lidar M, Giat E, Garelick D, et al. Rheumatic manifestations among cancer patients treated with immune checkpoint inhibitors. Autoimmun Rev. 2018;17(3):284-9. https://doi.org/10.1016/j.autrev. 2018.01.003.

19. Rischin A, Brady B, McLean C, Ostor AJK. Immune checkpoint inhibitor-induced lymphocytic fasciitis. Intern Med J. 2018;48(12):1550-2. https://doi.org/ 10.1111/imj.14126.

20. Le Tallec E, Ricordel C, Triquet L, et al. An original case of an association of eosinophilic fasciitis with cholangitis induced by nivolumab. J Thorac Oncol. 2019;14(1):e13-5. https://doi.org/10.1016/j.jtho. 2018.09.016.

21. Ollier N, Tournier E, Meyer N, et al. Nivolumabinduced eosinophilic fasciitis: a case report. Rheumatol Adv Pract. 2020;4(1):1-3. https://doi. org/10.1093/rap/rkaa001.

22. Andrés-Lencina JJ, Burillo-Martínez S, AragónMiguel R, et al. Eosinophilic fasciitis and lichen sclerosus in a patient treated with nivolumab. Australas J Dermatol. 2018;59(4):e302-4. https:// doi.org/10.1111/ajd.12836.

23. Toussaint F, Hammon M, Erdmann $M$, et al. Checkpoint inhibitor-induced eosinophilic fasciitis following high eosinophilia associated with complete response. Rheumatol (United Kingdom). 2019;58(10):1875-7. https://doi.org/10.1093/ rheumatology/kez164.

24. Daoussis D, Kraniotis P, Liossis SN, Solomou A. Immune checkpoint inhibitor-induced myo-fasciitis. Rheumatol (United Kingdom). 2017;56(12): 2161. https://doi.org/10.1093/rheumatology/ kex369.

25. Kobak S. Pembrolizumab-induced seronegative arthritis and fasciitis in a patient with lung 
adenocarcinoma. Curr Drug Saf. 2019;14(3):225-9. https://doi.org/10.2174/

1574886314666190528121039.

26. Narváez J, Juarez-López P, LLuch J, et al. Rheumatic immune-related adverse events in patients on antiPD-1 inhibitors: fasciitis with myositis syndrome as a new complication of immunotherapy.
Autoimmun Rev. 2018;17(10):1040-5. https://doi. org/10.1016/j.autrev.2018.05.002.

27. Daoussis D, Kraniotis P, Filippopoulou A, et al. An MRI study of immune checkpoint inhibitor-induced musculoskeletal manifestations myofasciitis is the prominent imaging finding. Rheumatol (United Kingdom). 2020;59(5):1041-50. https:// doi.org/10.1093/rheumatology/kez361. 